\title{
MALDI Imaging of Neutral Cuticular Lipids in Insects and Plants
}

\author{
Vladimír Vrkoslav, ${ }^{a}$ Alexander Muck, ${ }^{\mathrm{b}}$ Josef Cvačka, ${ }^{\mathrm{a}}$ and Aleš Svatoš ${ }^{\mathrm{b}}$ \\ ${ }^{a}$ Institute of Organic Chemistry and Biochemistry, Academy of Sciences of the Czech Republic, Prague, \\ Czech Republic \\ ${ }^{\mathrm{b}}$ Max Planck Institute for Chemical Ecology, Mass Spectrometry Group, Jena, Germany
}

The spatial distribution of neutral lipids and hydrocarbons has been imaged using MALDITOF mass spectrometry on intact plant and insect surfaces, namely wings and legs of the gray flesh fly (Neobellieria bullata), wings of common fruit fly (Drosophila melanogaster), leaves of thale cress (Arabidopsis thaliana), and leaves of date palm tree (Phoenix sp.). The distribution of wax esters (WEs) and saturated and unsaturated hydrocarbons (HCs) was visualized. The samples were attached on a target and multiply sprayed with lithium or sodium 2,5dihydroxybenzoate. The deposits were homogenous, consisting of small islands $(50-150 \mu \mathrm{m})$ of matrix crystals separated by small areas $(10 \mu \mathrm{m})$ of uncovered cuticle. Samples of N. bullata wings were found to contain HCs and WEs distributed close to their basal parts. The distribution of sodium and potassium ions was visualized on samples prepared by sublimation of 2,5-dihydroxybenzoic acid. Pheromonal dienes were detected on $D$. melanogaster female wings. A homogenous distribution of saturated WEs was observed on A. thaliana and Phoenix sp. leaf samples. The optimum number of laser shots per pixel was found to be higher than for polar compounds imaging. (J Am Soc Mass Spectrom 2010, 21, 220-231) (c) 2010 American Society for Mass Spectrometry

$\mathrm{T}$ The external surface of insects and higher vascular plants is covered by a waxy layer that serves a variety of functions. It protects living organisms against wear, dehydration or increased water intake, ultraviolet radiation, and bacterial and fungal pathogens. The wax contains a wide range of compounds.

Insect cuticular lipids consist mostly of hydrocarbons (HCs), wax esters (WEs), and sterol esters, ketones, alcohols, aldehydes, and acids [1, 2]. Insect cuticular HCs are synthesized by an elongation-decarboxylation pathway in oenocytes, which are associated with epidermal cells or fat bodies. After synthesis, HCs are transported through hemolymph by lipophorin carrier [3, 4]. Cuticular lipid profiles, which are species-specific both in solitary and social insects, serve as fingerprints, making it possible to discriminate species taxonomically or to recognize sibling species. Cuticular lipids are also known to play a semiochemical function in insects $[4,5]$ and to participate in a variety of plant-insect interactions [6, 7]. HCs are considered to be the main signals responsible for nestmate recognition in social insects $[4,8]$ and flies [9]. Plant epicuticular waxes are mainly made of long-chain aliphatic components, including primary and secondary alcohols, aldehydes, ketones, acids, $\mathrm{HCs}$, and various esters [10-12]. Their biosynthesis occurs in epidermal

Address reprint requests to Dr. Aleš Svatoš, Max Planck Institute for Chemical Ecology, Mass Spectrometry Group, Hans-Knöll-Str. 8, D-07745 Jena, Germany. E-mail: svatos@ice.mpg.de.

Dr. Josef Cvačka, Institute of Organic Chemistry and Biochemistry, Academy of Sciences of the Czech Republic, Flemingovo nám. 2, CZ-166 10, Prague, Czech Republic. E-mail: cvacka@uochb.cas.cz. tissues by elongating fatty acid precursors (C16 or C18) [13]. The full mechanism of plant wax formation and its regeneration is still being discussed. Evidence suggests wax components are transported through the polymer membrane together with water vapor [14]. The composition of cuticular waxes is greatly variable among plant species, organs of one species, and during organ ontogeny. Environmental factors, such as humidity or temperature, mostly affect only the total amount of wax, not its chemical composition [15].

The composition of cuticular lipids was studied after lipids were washed with organic solvents using various analytical techniques, mostly chromatographic and spectroscopic [16]. Compounds amenable to gas chromatography (GC) were analyzed directly, whereas the less volatile ones had to be hydrolyzed before analysis [17]. Simple neutral lipids, such as wax and cholesteryl esters or acylglycerols, can be qualitatively and quantitatively analyzed using electrospray, atmospheric pressure chemical ionization (APCI), or photoionization (APPI) mass spectrometry [18]. Like chromatographic methods, matrixassisted laser desorption/ionization time-of-flight mass spectrometry (MALDI-TOF MS) is increasingly important in lipid analysis [19]. Numerous studies have shown that both 2,5-dihydroxybenzoic acid (DHB) and its alkaline metal salts work well as matrices for neutral lipids [2023]. More recently, cryostripping the epicuticular lipid layer from plants was introduced [24], enabling epicuticular layer compositions to be analyzed directly.

Insect cuticular waxes usually form only a thin amorphous layer that lacks crystalline features. However, most 
scale insects secrete waxy coatings for their defense that exhibit distinct structures, such as tangled or curled filaments $[25,26]$. Little is known about the spatial distribution of cuticular wax on various organs or parts of insect bodies. Plant cuticular waxes form complex microstructures that originate from self-assembly processes [15]. Morphology of epicuticular wax crystals are determined by predominating compound or a class of major compounds in the wax. Epicuticular wax structures are of micrometer sizes and adopt various shapes, e.g., tubules, platelets, or rodlets.

To better understand the composition, morphology, and function of the protective cuticular waxy layer in plants and insects, the chemical composition of surface lipids should be directly linked to its location within an organism, organ, or tissue. Because such information can be provided by mass spectrometry imaging techniques, these have been increasingly used to study the spatial distribution of different molecules in biological systems ranging from whole animal tissue sections to single cells [27]. Secondary ion mass spectrometry (SIMS) has the longest history in surface visualization. SIMS offers a very high spatial resolution with submicrometer spot sizes. Recently, several impressive SIMS imaging applications of lipids in tissues or even single cells have been published [28-30]. Currently, the majority of biological imaging experiments are carried out using MALDI. Although in comparison to SIMS, MALDI offers lower spatial resolution (spots $\sim 25 \mu \mathrm{m}$ or more), higher sensitivity, substantially larger mass range, and the widespread availability of the instrumentation make MALDI imaging very attractive. The sample is scanned with a laser beam across a selected area and mass spectra are collected for each irradiated spot. The imaged objects are mostly tissue slices covered by a matrix. The quality of the resulting images strongly depends on the matrix deposition procedures [31-34]. MALDI imaging is mostly used for visualizing proteins or peptides [27, 35, 36], but recently MALDI imaging has been used with smaller molecules, e.g., drugs [37-39], secondary metabolites [40], or lipids [34, 41-44]. Mass spectrometry imaging has the potential to provide crucial insight into the function of cuticular lipids on surfaces of intact plants, insects, or other living organisms. However, so far only limited research has been done in this area [12].

Here we demonstrate how MALDI can be used to image neutral lipids on intact plant and insect surfaces. Various body parts of flies and leaves were probed to visualize the distribution of saturated and unsaturated HCs and WEs. Matrix deposition and sample preparation procedures are discussed in detail.

\section{Experimental}

\section{Insect and Plant Material}

Adults (both sexes, 2-14 d old) of gray flesh flies, Neobellieria bullata (Parker, 1916) (Diptera: Sarcophagidae), previously know as Sarcophaga bullata, were from laboratory breeding in the Institute of Organic Chemistry and Biochemistry, Prague. Common fruit flies, Drosophila melanogaster (Meigen, 1830) (Diptera, Drosophilidae) were from colony maintained in the MPI for Chemical Ecology, strain Canton S. Wings of ca. $6 \mathrm{~d}$ old females were detached under magnification by scissors. Insects were immobilized at low temperatures $\left(-18^{\circ} \mathrm{C}\right)$ before samples were prepared. Mature leaves from 4-wk-old, rosette-stage thale cress (Arabidopsis thaliana) of the Columbia accession (Col-0) were used. Plants were grown in a soil:vermiculite mixture (3:1) in a controlled environment chamber at $21^{\circ} \mathrm{C}, 55 \%$ relative humidity, $100 \mu \mathrm{mol} \mathrm{m} \mathrm{m}^{-2} \mathrm{~s}^{-1}$ photosynthetically active radiation from a mixture of Fluora and Cool White lamps (Osram, München, Germany), and a diurnal cycle of $10 \mathrm{~h}$ light and $14 \mathrm{~h}$ dark. A young leaf was detached from the main branch of indoor date palm tree (Phoenix sp.) maintained at living room conditions in Jena. The leaves were cut both crosswise and lengthwise using a scalpel to get samples $2 \times 10 \mathrm{~mm}$ each of which had one original leaf edge.

\section{Chemicals}

DHB was purchased from Sigma-Aldrich. Other matrices, lithium 2,5-dihydroxybenzoate (LiDHB) and sodium 2,5dihydroxybenzoate $(\mathrm{NaDHB})$, were synthesized by neutralizing DHB as described [21, 23]. For imaging cheap LiDHB of natural isotopic composition was used, for analysis of extracts or purified fraction ${ }^{6} \mathrm{LiDHB}$ matrix was employed. High purity solvents (hexane, chloroform, dichloromethane, and acetone) were supplied by Merck (Darmstadt, Germany), Carl-Roth (Karlsruhe, Germany), or Riedel-de Haen and used as received. Diethyl ether (Penta; Prague, Czech Republic) was further purified by distillation. Poly(ethylene glycol) oligomers (PEG; with average masses 200, 300, 600, and $1000 \mathrm{Da}$ ) for the calibration of the mass spectrometer were purchased from SigmaAldrich. Bees wax esters were from our stock, prepared as published [23].

\section{Isolation of Neutral Lipids for Analysis}

Wings and legs were detached from immobilized $\left(-18^{\circ} \mathrm{C}\right) 30$ males and 30 females of $N$. bullata and placed for $15 \mathrm{~min}$ in a desiccator to remove surface moisture. Lipids were extracted with dichloromethane $(4 \times 0.5 \mathrm{~mL}, 1 \mathrm{~min})$ in a small glass vial. The volume of solvent was reduced under a stream of argon. The total extract was fractionated onto precleaned glass thinlayer chromatography (TLC) plates $(36 \times 76 \mathrm{~mm})$ coated with Adsorbosil-plus (layer thickness $0.2 \mathrm{~mm}$ with gypsum (12\%); Applied Science Labs, State College, PA, USA) using hexane as the mobile phase. Spots were visualized by spraying rhodamine $6 \mathrm{G}$ solution $(0.05 \%$ in ethanol) onto plates, scraping them off the plates and extracting them with diethyl ether $(6-8 \mathrm{~mL})$. HCs were obtained from the upper part of the TLC plates $\left(R_{F} 0.5-1.0\right)$, more polar lipids from the lower 
part $\left(R_{F} 0-0.5\right)$. Diethyl ether was removed under a stream of argon; residues were weighed and re-dissolved in dichloromethane to a concentration of $1 \%$ $(w t)$. Polar fractions were further separated using hexane:diethyl ether (80:20, vol/vol) mobile phase to isolate WEs $\left(\mathrm{R}_{\mathrm{F}}\right.$ 0.90-0.95). The Phoenix sp. leaf was allowed to dry in a desiccator, washed with $1 \mathrm{~mL}$ of dichloromethane, and the extract was separated as described for N. bullata.

\section{Analysis of Lipid Extracts by MALDI/TOF}

Lipid extracts were analyzed using Reflex IV (Bruker Daltonik, Ltd., Bremen, Germany) operated in reflectron mode with the acceleration voltage of $20 \mathrm{kV}$ and $200 \mathrm{~ns}$ ion extraction pulse. Desorption and ionization were achieved using a nitrogen UV laser $(337.1 \mathrm{~nm}, 4 \mathrm{~ns}$ pulse of $300 \mu \mathrm{J}$, maximum frequency $20 \mathrm{~Hz}$ ). Matrix ions were suppressed below $\mathrm{m} / \mathrm{z} 300$. Data were collected and analyzed using FlexAnalysis 3.0 software (Bruker Daltonics). Spectra were averaged from 800 (WEs) or 1200 (HCs) laser shots. The stainless steel MALDI target plates were thoroughly cleaned by sonication in acetone, dichloromethane and hexane $(5 \mathrm{~min}$ each) and rinsed with diethyl ether to remove eventual contaminants. The matrix ( $\left.{ }^{6} \mathrm{LiDHB}\right)$ was dissolved in acetone:chloroform (2:1, first adding acetone) at a concentration of $10 \mathrm{mg} / \mathrm{mL}$ and spotted $(0.7 \mu \mathrm{L})$ on the MALDI target. The solvent was allowed to evaporate and the sample $(0.7 \mu \mathrm{L})$ was applied on the top of the matrix (Ma/Sa method). External mass calibration was achieved using PEGs (average molecular masses of 200, 300,600 , and $1000 \mathrm{Da}$ ) in acetone, detected as lithiated $\left({ }^{6} \mathrm{Li}\right)$ adducts (Supplementary Table S1, which can be found in the electronic version of this article).

\section{MALDI Imaging}

MALDI imaging experiments were performed with MALDI Micro MX (Waters, Manchester, UK) operated in reflectron mode with the acceleration and plate voltages at -12 and $5 \mathrm{kV}$, respectively. Delayed extraction time was $500 \mathrm{~ns}$. Desorption and ionization were accomplished using nitrogen UV laser (337 nm, 4 ns pulse of maximum $320 \mu \mathrm{J}$ and a frequency of $20 \mathrm{~Hz}$ ). Matrix ions were suppressed with a low mass (300 Da or less) cut-off. External mass calibration was achieved using ${ }^{7} \mathrm{Li}^{+}$adducts of PEGs (Supplementary Tab. S1). Samples for MALDI imaging were attached to a stainless steel target plate using double-sided Scotch adhesive tape (product no 34-8509-3289-7, 3M, St. Paul, MN, USA). Extracts for MALDI imaging $(0.7 \mu \mathrm{L}, 10 \mathrm{mg} / \mathrm{mL})$ were applied to the stainless steel MALDI plate and allowed to dry. The fingerprint was made by left hand thumb. The thumb was impregnated by WEs extract from bee wax $(10 \mathrm{mg} / \mathrm{mL})$, allowed to dry and imprinted on the target plate. LiDHB matrix solutions were prepared in acetone:dichloromethane (9:1, vol/ vol) at a concentration of $20 \mathrm{mg} / \mathrm{mL}$. NaDHB matrix solutions were prepared in acetone at the same concentration. The samples were sprayed from a distance of $150 \mathrm{~mm}$ using a commercial airbrush with a $0.2 \mathrm{~mm}$ diameter sprayer jet. Three milliliters of matrix solutions were used to form 30 coats with waiting time of about $10 \mathrm{~s}$ between consecutive sprays. MALDI imaging of neutral lipids requires a relatively long time to get a signal. Therefore, the number of laser shots per pixel was optimized and set to $380(130 \mu \mathrm{J} / \mathrm{shot})$. Coating with DHB was achieved by sublimation in a glass container at $140{ }^{\circ} \mathrm{C} / 0.01$ Torr for $30 \mathrm{~min}$. A similar device was described previously [32]. The number of laser shots per pixel for samples coated with DHB was $150(130 \mu \mathrm{J} / \mathrm{shot})$. The samples were imaged using several step sizes (resolutions). The extracts spotted on the target plate were scanned with a step of $300 \mu \mathrm{m}(85$ dpi). Most of the insect and plant objects, including fingerprint were imaged at higher resolution of $127 \mathrm{dpi}$ (step size of $200 \mu \mathrm{m}$ ). The resolution was further increased to $254 \mathrm{dpi}$ (step size of $100 \mu \mathrm{m}$ ) for very small wings of D. melanogaster (wing area approximately 1 $\mathrm{mm}^{2}$ ). Data were collected with MassLynx 4.0 and processed with custom-made software MALDI Image Convertor (Waters, Manchester, UK). We did not have commercial software for processing MALDI imaging data. Therefore, the data were processed by the sequence of operations: ASCII data representing selected ion chromatograms (SIC) reconstructed for a monoisotopic mass within $0.20-0.45 \mathrm{Da}$ window were exported to Microsoft Excel for manual background subtraction. Finally, the data were exported to ImageJ (National Institutes of Health, Bethesda, MD, USA) and converted into two-dimensional ion intensity maps. The spectral intensities were normalized automatically within the 0-255 range in ImageJ.

\section{Analysis of Lipid Extracts by GC/MS}

GC/MS analyses were performed on a $6890 \mathrm{~N}$ gas chromatograph coupled to a 5975B mass spectrometer, equipped with electron ionization (EI) and quadrupole analyzer (Agilent Technologies, Santa Clara, CA, USA). The lipid extracts $(5 \mu \mathrm{L}, 2.5 \mathrm{mg} / \mathrm{mL}$ in dichloromethane) were injected manually in the splitless mode. An HP5-MS fused silica capillary column $(30 \mathrm{~m} \times 250 \mu \mathrm{m}$; film thickness $0.25 \mu \mathrm{m}$, Agilent Technologies) was used for separations. The carrier gas was helium at a constant flow rate of $2.5 \mathrm{~mL} / \mathrm{min}$. Temperature program: $60^{\circ} \mathrm{C}$ (2 min), then $10{ }^{\circ} \mathrm{C} / \mathrm{min}$ to $260^{\circ} \mathrm{C}$, then $2{ }^{\circ} \mathrm{C} / \mathrm{min}$ to $320^{\circ} \mathrm{C}$ (70 min). The injector, transfer line, and EI source temperatures were $260^{\circ} \mathrm{C}, 320^{\circ} \mathrm{C}$, and $230^{\circ} \mathrm{C}$, respectively. Mass spectra were recorded from 25 to $900 \mathrm{~m} / \mathrm{z}$. WEs from N. bullata were methanolyzed to alcohols and fatty acid methyl esters (FAMEs) according to a published method [45], and the reaction products were analyzed by GC/MS. The temperature program: $40^{\circ} \mathrm{C}$ (1 min), $50{ }^{\circ} \mathrm{C} / \mathrm{min}$ to $140{ }^{\circ} \mathrm{C}$, then $3{ }^{\circ} \mathrm{C} / \mathrm{min}$ to $320^{\circ} \mathrm{C}$ (20 $\mathrm{min}$ ), the carrier gas flow rate was $1 \mathrm{~mL} / \mathrm{min}$. The injector, transfer line, and EI source temperatures were 
$240{ }^{\circ} \mathrm{C}, 250^{\circ} \mathrm{C}$, and $230{ }^{\circ} \mathrm{C}$, respectively. Mass spectra were recorded from 25 to $600 \mathrm{~m} / \mathrm{z}$.

\section{High-Resolution Electrospray MS}

The exact masses of WEs were measured using a Thermo Fisher Scientific (Bremen, Germany) LTQ Orbitrap XL hybrid mass spectrometer equipped with an electrospray ion source. Methanol was used as mobile phase at a flow rate of $0.2 \mu \mathrm{L} / \mathrm{min}$. The samples were dissolved in dichloromethane, diluted with the mobile phase and injected using a 2- $\mu$ l loop. Capillary voltage, tube lens voltage, and capillary temperature were 10, 165 , and $300{ }^{\circ} \mathrm{C}$, respectively. The chemical identity of the compounds encountered was confirmed by collision induced dissociation (CID experiment at $17 \mathrm{~V}$ normalized energy) mass spectrometry on an LTQ Orbitrap XL with an AP-MALDI source equipped with a solid-state NdYAG UV laser (MassTech, Columbia, MD, USA) and running Target 6 (MassTech) and Excalibur ver. 2.0 (Thermo) software for data acquisition.

\section{Scanning Electron Microscopy}

The morphology of samples before and after coating with the matrix was examined by scanning electron microscopy (SEM) using JSM-6380LV instrument (JEOL, Tokyo, Japan). The samples were fixed onto the aluminum stab using conductive double-sided tape and sputtered with gold (nm thickness). SEM images were made using acceleration voltage $12-15 \mathrm{kV}$ and spot size $42-50 \mu \mathrm{m}$.

\section{Results and Discussion}

\section{Identification of Cuticular Lipids}

Neutral cuticular lipids were first probed by mass spectrometry to learn about the identity of the main components. Based on TLC analysis, WEs and HCs were found to be abundant classes of neutral lipids in all samples.

MALDI revealed that $N$. bullata possess WEs mostly containing even number of carbons $34-54$ and $0-2$ double bonds (Supplementary Fig. S1a). Two abundant signals at $m / z 652.6$ and 680.6 (both $\left[\mathrm{M}+{ }^{6} \mathrm{Li}\right]^{+}$) were later used for the construction of mass images. WEs isolated from N. bullata wings were further studied by GC/MS and ESI-MS. GC showed several peaks eluting at higher temperatures. EI mass spectra exhibited typical features for WEs [46] including molecular ion $\mathrm{M}^{+}$, protonated fatty acid $\mathrm{RCOOH}_{2}^{+}$, acylium ions $\mathrm{RCO}^{+}$ (saturated) or radical cation $[\mathrm{RCO}-\mathrm{H}]^{+\cdot}$ (mono- and di-unsaturated) and ions related to the alcoholic part of WE molecules, $\left[\mathrm{R}^{\prime}-\mathrm{H}\right]^{+\cdot}$. In ESI-MS, unsaturated WEs provided sodium adducts, which were used for elemental composition assignment. Saturated esters did not provide adducts under ESI conditions. Selected data are shown in Supplementary Table. S2 and Figure S2. We found that WEs of $N$. bullata are mostly composed of fatty acids with 16 and 18 carbons and $0-1$ double bonds and saturated alcohols C18-C30. Methyl esters of these fatty acids and the alcohols were identified as the products of methanolysis of the original sample of WEs (Supplementary Figure S3). Exact mass measurement of sodium adducts in ESI confirmed expected elemental compositions of WEs (mass errors bellow 2.0 ppm). Our data agree with previously published results [47]. HCs of $N$. bullata have been studied since the 1970s [22, 47, 48]. As our previous findings led us to expect [22], the MALDI spectra provided evidence of saturated and unsaturated HCs with odd and even numbers of carbons (Supplementary Figure S1b). The most intense peaks $\left(\mathrm{m} / \mathrm{z}\right.$ of $\left.\left[\mathrm{M}+{ }^{6} \mathrm{Li}\right]^{+}\right)$were found at $\mathrm{m} / \mathrm{z} 428.5$ $\left(\mathrm{C}_{30} \mathrm{H}_{62}\right.$, a mixture of methylnonacosanes [48], $\mathrm{m} / \mathrm{z} 550.6$ $\left(\mathrm{C}_{39} \mathrm{H}_{76}\right.$, diene), and $m / z 578.6\left(\mathrm{C}_{41} \mathrm{H}_{80}\right.$, diene $)$. The fragmentation spectra of laser-desorbed ions were obtained on Orbitrap instrument using AP-MALDI source. Accurate mass of two precursor ions were measured (653.67798; $\mathrm{C}_{44} \mathrm{H}_{86} \mathrm{O}_{2}{ }^{7} \mathrm{Li}$, and 681.70758; $\left.\mathrm{C}_{46} \mathrm{H}_{90} \mathrm{O}_{2}{ }^{7} \mathrm{Li}\right)$. Upon ion-trap CID experiment, those two precursors show $m / z 289$ and 261 fragments representing oleic (18:1) and palmitoleic (16:1) acid ${ }^{7} \mathrm{Li}$ adduct ions, fully collaborating with data from GC/MS and ESI/MS (Supplemental Table 2, entries 11 and 13, respectively).

Composition of cuticular HCs of D. melanogaster, its function, and variation were described in several papers $[9,49,50]$. D. melanogaster females synthesize long-chain hydrocarbons with various degrees of saturation $\left(\mathrm{C}_{27} \mathrm{H}_{52}, \mathrm{C}_{27} \mathrm{H}_{54}, \mathrm{C}_{29} \mathrm{H}_{56}, \mathrm{C}_{29} \mathrm{H}_{58}\right)$.

Based on MALDI spectra of Phoenix sp. leaves extracts, WEs had almost exclusively even number of carbons (32-64). Esters with lower molecular weights were mostly saturated, whereas those at higher $m / z$ values were singly or doubly unsaturated (Supplementary Figure S1c). According to the GC/MS analysis, the most abundant saturated WEs (i.e., $\mathrm{C}_{46} \mathrm{H}_{92} \mathrm{O}_{2}, \mathrm{C}_{48} \mathrm{H}_{96} \mathrm{O}_{2}$, and $\mathrm{C}_{50} \mathrm{H}_{100} \mathrm{O}_{2}$ ) contained a fatty acid with an even number of carbons, namely C16:0, C20:0, C22:0, C24:0, and C26:0. Interestingly, C18:0 was missing. Almost the same fatty acids predominate in WEs of Phoenix canariensis [51].

WEs of $A$. thaliana cer mutants, Landsberg erecta and Wassilewskija wild type were reported recently [52]. WEs with chain lengths between 38 and 52 carbons were identified. Esters with even number of carbons prevailed, with 42,44 , and 46 carbons favored in the wild types.

An overview of the compounds that were used to construct the mass images is given in Table 1 .

\section{MALDI Imaging of Lipid Extracts Deposited on Target}

Before starting to image biological objects, the methodology was tested with lipid extracts isolated from the surface of various parts of the N. bullata body. Numerous reports have shown that the quality of sample preparation affects the quality of spectra. We have 
Table 1. An overview of $\mathrm{m} / \mathrm{z}$ values of ions used for constructing images

\begin{tabular}{|c|c|c|c|c|c|c|c|c|}
\hline \multirow[t]{2}{*}{ Ion } & \multicolumn{4}{|c|}{ Neobellieria bullata } & \multicolumn{4}{|c|}{ Phoenix sp. } \\
\hline & $\mathrm{C}_{30} \mathrm{H}_{62}$ & $\mathrm{C}_{39} \mathrm{H}_{76}$ & $\mathrm{C}_{41} \mathrm{H}_{80}$ & $\mathrm{C}_{44} \mathrm{H}_{86} \mathrm{O}_{2}$ & $\mathrm{C}_{46} \mathrm{H}_{90} \mathrm{O}_{2}$ & $\mathrm{C}_{46} \mathrm{H}_{92} \mathrm{O}_{2}$ & $\mathrm{C}_{48} \mathrm{H}_{96} \mathrm{O}_{2}$ & $\mathrm{C}_{50} \mathrm{H}_{100} \mathrm{O}_{2}$ \\
\hline$\left[\mathrm{M}+{ }^{6} \mathrm{Li}\right]^{+}$ & 428.5 & 550.6 & 578.6 & 652.7 & 680.7 & 682.7 & 710.7 & 738.8 \\
\hline$\left[\mathrm{M}+{ }^{7} \mathrm{Li}\right]^{+}$ & 429.5 & 551.6 & 579.6 & 653.7 & 681.7 & 683.7 & 711.7 & 739.8 \\
\hline$[\mathrm{M}+\mathrm{Na}]^{+}$ & - & - & - & 669.6 & 697.7 & - & - & - \\
\hline$[\mathrm{M}+\mathrm{K}]^{+}$ & - & - & - & 685.6 & 713.7 & - & - & - \\
\hline \multirow[t]{2}{*}{ Ion } & & beeswa) & & \multicolumn{3}{|c|}{ Drosophila melanogaster } & \multicolumn{2}{|c|}{ Arabidopsis thaliana } \\
\hline & & $\mathrm{C}_{40} \mathrm{H}_{80} \mathrm{O}$ & & $\mathrm{C}_{27} \mathrm{H}_{52}$ & \multicolumn{2}{|c|}{$\mathrm{C}_{29} \mathrm{H}_{56}$} & \multicolumn{2}{|c|}{$\mathrm{C}_{46} \mathrm{H}_{92} \mathrm{O}_{2}$} \\
\hline$\left[\mathrm{M}+{ }^{7} \mathrm{Li}\right]^{+}$ & & 599.6 & & 383.4 & \multicolumn{2}{|c|}{411.4} & \multicolumn{2}{|c|}{683.7} \\
\hline
\end{tabular}

demonstrated $[21,23]$ that for neutral lipids, the deposition of sample and matrix $(\mathrm{Sa} / \mathrm{Ma})$ on a stainless steel target gives high quality spectra. For WEs, even better results were obtained when the matrix and samples were deposited in reverse order $(\mathrm{Ma} / \mathrm{Sa})$, but this is not applicable for imaging. For our imaging experiments, we compared the proven Sa/Ma method and its modified version. Nonpolar and polar fractions of the total lipid extract were deposited on a stainless steel target. Half of the spots were covered by LiDHB using the Sa/Ma technique (Figure 1a, upper line (1-3), and the second half was sprayed with LiDHB solution using an airbrush (Figure 1a, lower line (4-6). Both parts of the target were imaged by MALDI-TOF (results are shown in Figure $1 b-f)$. Both sample preparation methods on nonpolar fractions isolated from legs and deposited in positions 1 and 4 provided signals of lithiated HCs of similar intensity. Mass images of lithium adducts of two selected dienes [22], $\mathrm{C}_{39} \mathrm{H}_{76}(\mathrm{~m} / \mathrm{z} 551.6)$ and $\mathrm{C}_{41} \mathrm{H}_{80}(\mathrm{~m} / \mathrm{z}$ 579.6), are shown in Figure 1c, d. Similar results were obtained when a nonpolar fraction isolated from the wings was probed. Polar lipids containing oxygen are more amenable to the cationization reaction [21,23] and should be easily detected in the extracts. The ion image at $\mathrm{m} / \mathrm{z} 653.7$ (Figure 1e) and $\mathrm{m} / \mathrm{z} 681.7$ (Figure 1f) corresponding to lithiated monounsaturated wax ester $\mathrm{C}_{44} \mathrm{H}_{86} \mathrm{O}_{2}$ and $\mathrm{C}_{46} \mathrm{H}_{90} \mathrm{O}_{2}$, respectively, confirms this expectation. The lower part of the total ion image (all ion intensity summed, Figure $1 \mathrm{~b}$ ) shows that spraying the matrix give homogenous signal from the sample spot as well as from surrounding. Surrounding signal was constituted of matrix ions. In case of hydrocarbons, homogeneity was better for sprayed spot, then for typically prepared spots. The effect is not so obvious for more polar analytes. Because analytes concentrate near the edge due to the fast evaporation of solvent after spotting on the target plate, differences between center and edge signals were observed. To study analyte delocalization during sample spraying and further handling, we printed a mixture of WEs isolated from beeswax [23] using a finger. This "wax dactyloscopy" yielded well resolved prints, when observed under microscope (Figure $1 \mathrm{~g}$ ). The individual papillary lines (ca, $0.5 \mathrm{~mm}$ thick) are separated by ca, $0.3 \mathrm{~mm}$ areas without WEs depo- sition. This print was sprayed 30 times with LiDHB and submitted to MALDI imaging. The image was reconstructed for WE $m / z 599.6\left(\mathrm{C}_{40} \mathrm{H}_{80} \mathrm{O}_{2}\right.$, [23] (Figure 1h). The Figure $1 \mathrm{~h}$ consists of spots that correspond to step size of laser $200 \mu \mathrm{m}$. However, texture of fingerprint could be recognized because the papillary lines were separated by empty blanks and the overall characteristic was fully preserved. The loss of resolution due to analytes delocalization during sample spraying was not observed. If the matrix ion $\mathrm{m} / \mathrm{z} 161.0\left([\mathrm{LiDHB}+\mathrm{H}]^{+}\right)$is displayed, no fine structures are visible (Figure 1i). In conclusion, spraying LiDHB solution seems to be an appropriate technique for depositing the matrix and allowing HCs and WEs to be reliably detected in imaging experiments.

\section{MALDI Imaging of Wings and Legs of $\mathrm{N}$. bullata}

Wings (both dorsal and ventral sides) and legs (tarsus) of $N$. bullata were attached to a stainless steel MALDI target using double-sided tape. The samples were multiply sprayed with $\mathrm{LiDHB}$ or $\mathrm{NaDHB}$ solution prepared in chloroform/acetone. Individual sprays were brief and the tissue was never allowed to become wet, to prevent lipids from delocalizing. Coating was performed 6-, 9-, 12-, and 30 times and intensities of lipid signals were compared. Thirty consecutive sprayings left homogenous deposits consisting of small islands (50-150 $\mu \mathrm{m}$ in diameter) of matrix material separated by small areas (ca. $10 \mu \mathrm{m}$ in diameter) of uncovered cuticle (Figure 2) and provided the highest signal intensities. The sample delocalization during/after the matrix spraying, which will blur the images, was excluded (see above). The cover probably resulted from very small droplets created in $200 \mu \mathrm{m}$ air-brush nozzle; these subsequently merged into bigger islands upon multiple sprays. The cover thickness was estimated to be 10-20 $\mu \mathrm{m}$ by comparing the size of fine hairs on wings when free or covered by matrix. The imaging was performed at a resolution of $127 \mathrm{dpi}$ (step size of $200 \mu \mathrm{m}$ ) and the matrix coating was fine enough to prevent any distortion of mass images. An example of MALDI spectra taken from an imaged wing of N. bullata can be found in Figure $3 \mathrm{~g}$. The spectrum was taken form a place showing the most intense peak of hydrocarbons. 


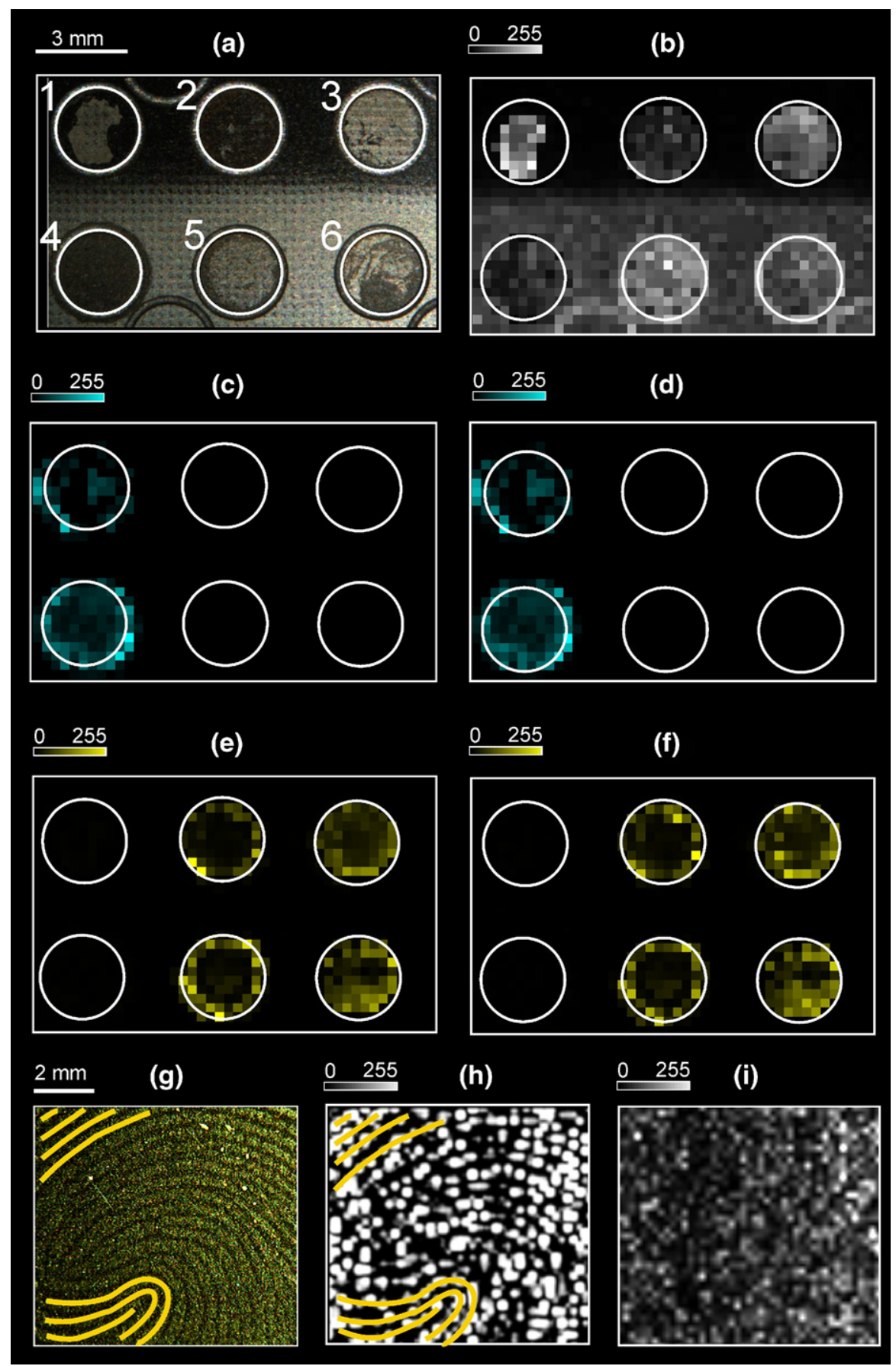

Figure 1. MALDI target with lipids isolated from legs $(1,2,4,5)$ and wings $(3,6)$ of $N$. bullata. Hydrocarbons were deposited in spots 1 and 4, more polar lipids in the remaining wells $(2,3,5$, and 6). The samples in the upper part of the target (1-3) were covered by LiDHB using the Sa/Ma technique; the samples in the lower part (4-6) were sprayed with LiDHB. Photograph of the target (after measurement) (a), MALDI images of the total ion current (b), lithium adduct of diene $\mathrm{C}_{39} \mathrm{H}_{76}$ at $\mathrm{m} / \mathrm{z} 551.6$ (c), lithium adduct of diene $\mathrm{C}_{41} \mathrm{H}_{80}$ at $m / z 579.6$ (d), lithium adduct of wax ester $\mathrm{C}_{44} \mathrm{H}_{86} \mathrm{O}_{2}$ at $m / z 653.7$ (e), and lithium adduct of wax ester $\mathrm{C}_{46} \mathrm{H}_{90} \mathrm{O}_{2}$ at $\mathrm{m} / \mathrm{z} 681.8$ (f). Photograph of "beeswax fingerprint" covered with LiDHB (g), MALDI images of lithium adduct of WEs $\mathrm{C}_{40} \mathrm{H}_{80} \mathrm{O}_{2}$ at $\mathrm{m} / \mathrm{z} 599.6$ (h), and matrix ion $\mathrm{m} / \mathrm{z} 161.0$ (i).

\section{Distribution of HCs}

Previous experiments (TLC isolation and subsequent analysis) indicated that both the legs and wings of $N$. bullata are covered by a waxy layer containing HCs. MALDI spectra of lithium adducts from isolated HC fractions (Figure 1c, d) provided strong signals not only for spots where Sa/Ma deposition method was used, but also for spray-over spots. However, the surface of living organisms is more complex and subject to various signal suppression/enhancement effects from other 


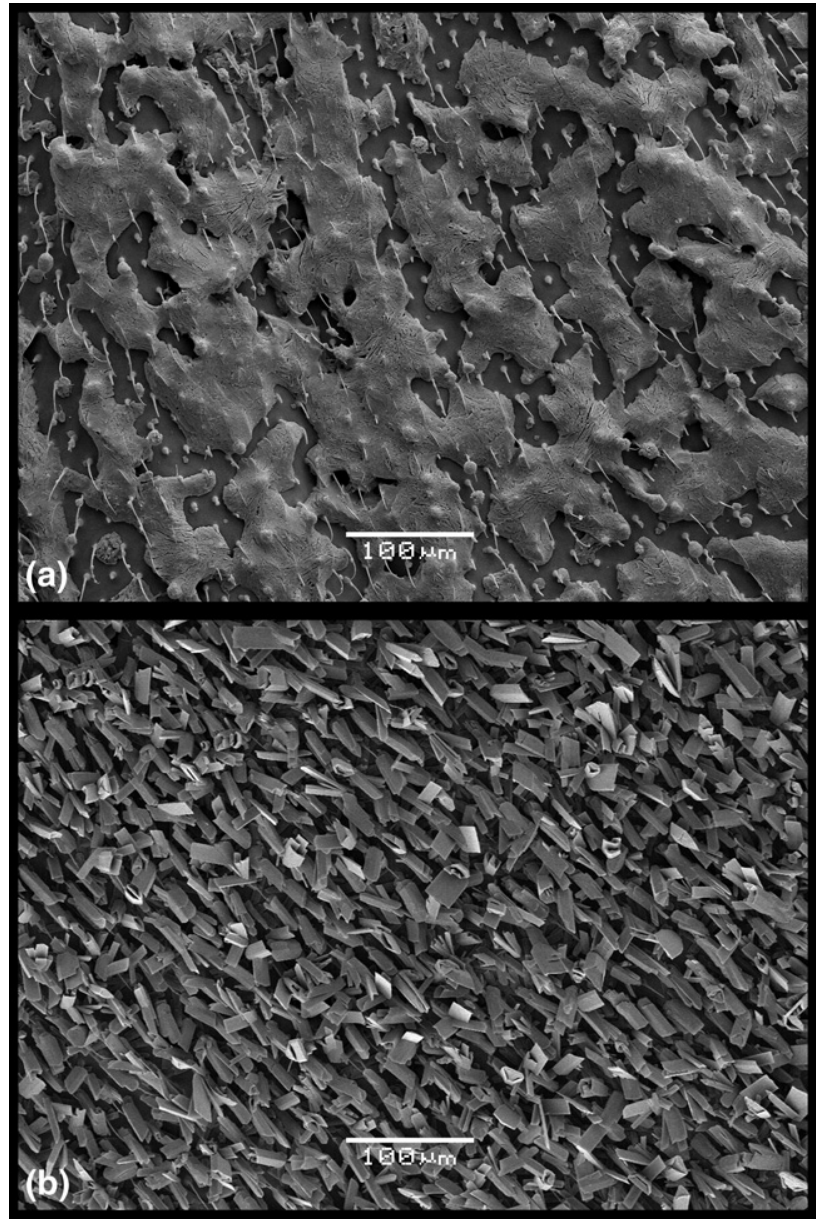

Figure 2. SEM images of matrix crystals deposited on dorsal side of $N$. bullata wing. LiDHB sprayed with an airbrush (a) and sublimated DHB (b).

compounds. From our previous studies [21, 22] it is apparent that spots must be irradiated by UV laser for a longer time than used usually, and more that 100 lasers shots are necessary to obtain clean spectra of lithiated HC. As the cuticle of plants and insects contains diverse classes of lipids with different polarity and, hence, high or low affinity to lithium cationization, the imaging on real sample is a challenging task. Nevertheless, our results clearly showed that insect cuticles could be fairly well imaged for HCs. The homogenous deposition of matrix on the wing surface is documented by optical microscope photography (Figure 3a). Unsaturated and even fully saturated HCs, forming adduct ions with most difficultly, were detected. Figure $3 \mathrm{~d}-\mathrm{f}$ shows two-dimensional ion intensity maps of both saturated $\left(\mathrm{m} / z \mathrm{z29.5},\left[\mathrm{C}_{30} \mathrm{H}_{62}+\mathrm{Li}\right]^{+}\right)$ and unsaturated $\left(m / z 551.6,\left[\mathrm{C}_{39} \mathrm{H}_{76}+\mathrm{Li}\right]^{+} ; m / z\right.$ 579.6, $\left.\left[\mathrm{C}_{41} \mathrm{H}_{80}+\mathrm{Li}\right]^{+}\right) \mathrm{HCs}$ on the dorsal side of a female wing. HCs were observed mostly near the basal part of the wings. The distribution of a matrix ion at $\mathrm{m} / \mathrm{z} 161.0$ (Figure 3c) is more homogeneous then distribution of analytes. Moreover, the most intensive spots of the analytes, which are placed on the basal part of the wings, are not observed on matrix ion figure. According to the distribution of analytes, the intensity is higher on the supporting veins. The effect is slightly more obvious for matrix ions, as well. It is difficult to recognize if the analytes concentration is higher on the supporting veins, or ionization is affected by different deposition of matrix on non-homogenous surface.

\section{Distribution of Wes}

Multiple signals corresponding to lithium adducts of WEs were observed on the dorsal side of female wings. Distribution of the dominant ion $\left[\mathrm{C}_{46} \mathrm{H}_{90} \mathrm{O}_{2}+\mathrm{Li}\right]^{+}(\mathrm{m} / \mathrm{z}$ 681.8 ) is shown in Figure 3i. The highest concentration of WEs was near the basal part of the wing (basicosta). In addition to the expected lithiated molecules, WEs adducts with sodium and potassium were also detected, e.g., $\left[\mathrm{C}_{46} \mathrm{H}_{90} \mathrm{O}_{2}+\mathrm{Na}\right]^{+}$at $m / z 697.7$, or $\left[\mathrm{C}_{46} \mathrm{H}_{90} \mathrm{O}_{2}+\mathrm{K}\right]^{+}$at $\mathrm{m} / \mathrm{z}$ 713.7. Their occurrence indicated a large number of sodium and potassium ions, which presumably form an integral part of the wing cuticle. When LiDHB was replaced by $\mathrm{NaDHB}$, the same distribution of WEs was observed (data not shown). Analogous mass images of WEs were observed also on the ventral sides and male wings. Closer inspection of the TIC image indicated that other compounds were detected as well, mostly near basicosta (Figure 3j). Some signals were assigned to triacylglycerols, which probably contaminated the surface during wing abscission. In addition, as-yet unknown ions (e.g., $m / z$ 560.6, 576.6, 604.6, 649.6, 675.7) were observed in various locations on the wings. The double-sided tape used in our experiments was found to suppress ion formation, which resulted in stronger signal of ions from imaged objects or stainless steel surface than from the bare tape (not shown).

\section{Distribution of Sodium and Potassium}

To confirm the presence of sodium and potassium on wings, we covered the samples with DHB. Unlike its salts, DHB can be easily deposited by sublimation [32]. DHB was sublimed onto a preparation of dorsal and ventral side of wings, low tarsus from a N. bullata male (Figure $4 \mathrm{~d}$ ). Coatings achieved by sublimation were even more uniform than those achieved by spraying (Figure 2). Molecular adducts of DHB with $\mathrm{H}^{+}, \mathrm{Na}^{+}$, and $\mathrm{K}^{+}$were observed (Figure $4 \mathrm{a}-\mathrm{c}$ ) at $\mathrm{m} / \mathrm{z}$ 155.0, 177.0, and 193.0, respectively. Interestingly, all the observed cations were distributed spatially in distinct patterns. We observed a quite homogenous distribution of sodium. According to Figure $4 \mathrm{c}$, more potassium was placed near the wing basicosta than on the edge parts of wings. It could be observed mainly on the ventral side of wing. High concentration of potassium was observed also on the tarsus. Higher intensities of $[\mathrm{DHB}+\mathrm{H}]^{+}$ were observed near the edge of the wing. Thus, the application of MALDI can be easily extended to studies of the distribution of alkali metals in the cuticle. The amounts of sodium and potassium on the wings were sufficient for 


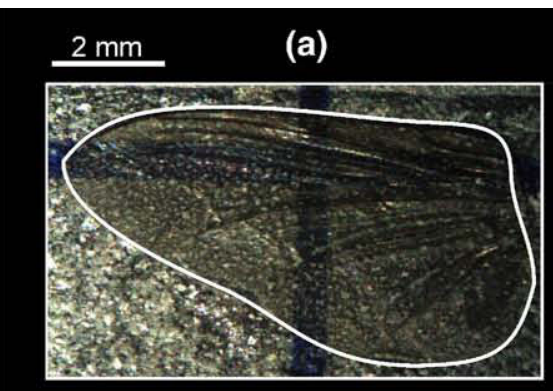

$0 \quad 255$

(d)

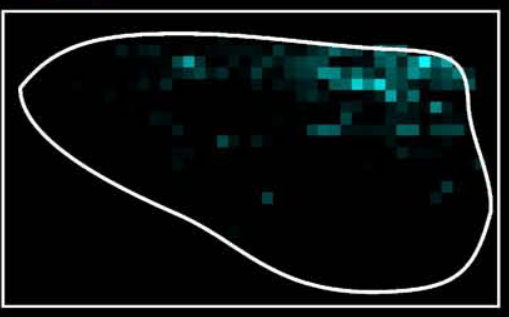

\section{$0 \quad 255$}

(b)

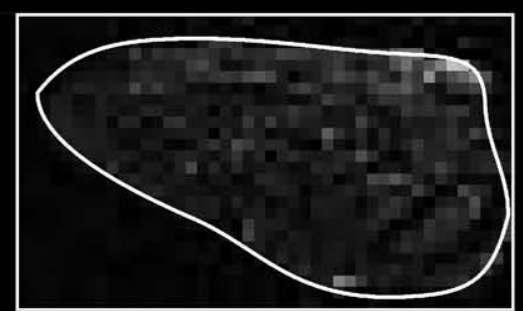

$0 \quad 255$

(e)

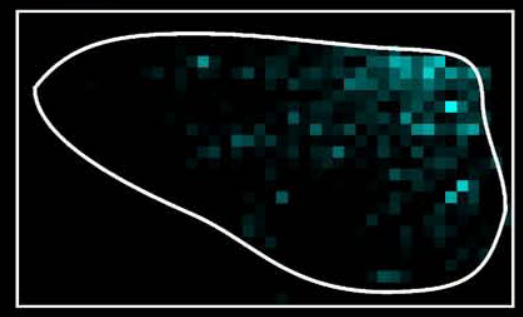

$0 \quad 255$

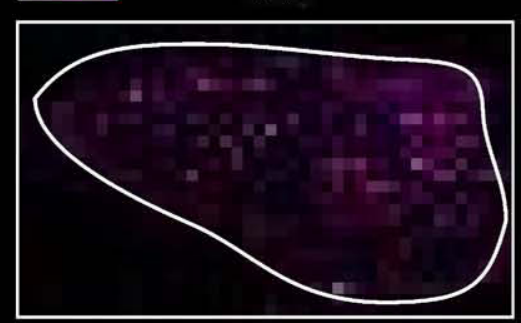

$0 \quad 255$

(f)

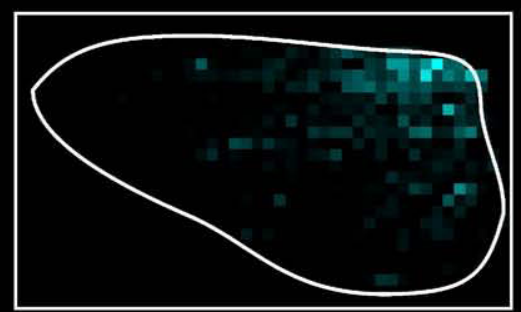

(g)

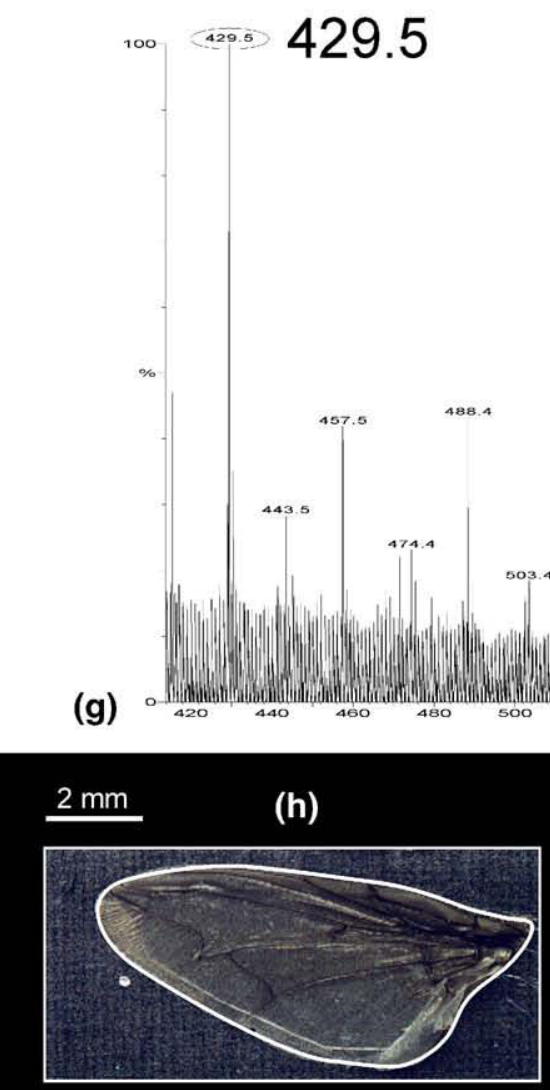

\section{$551.6 \quad 579.6$}

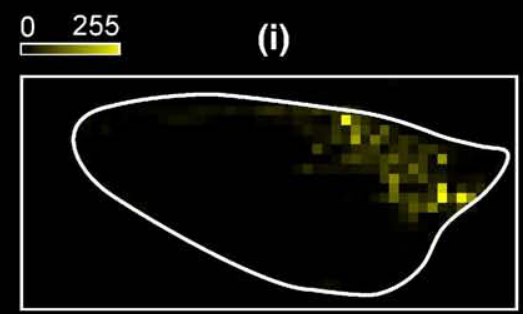

\section{7}

\section{7}

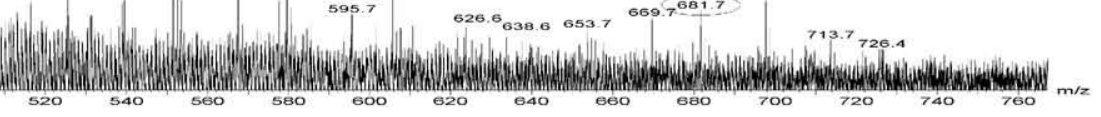

Figure 3. Photograph of the dorsal side of $N$. bullata female wing covered with LiDHB (after measurement) (a), MALDI images constructed for the total ion current (b), matrix ion $\mathrm{m} / \mathrm{z} 161.0$ (c), lithium adduct of saturated hydrocarbon $\mathrm{C}_{30} \mathrm{H}_{62}$ at $\mathrm{m} / z 429.5$ (d), diene $\mathrm{C}_{39} \mathrm{H}_{76}$ at $\mathrm{m} / z 551.6$ (e), and diene $\mathrm{C}_{41} \mathrm{H}_{80}$ at $\mathrm{m} / \mathrm{z} 579.6$ (f). An example of MALDI imaging spectrum of $\mathrm{N}$. bullata wing (g). Photograph of the dorsal side of $N$. bullata female wing covered with LiDHB (after measurement) (h), MALDI images constructed for lithium adduct of $\mathrm{WE} \mathrm{C}_{46} \mathrm{H}_{90} \mathrm{O}_{2}$ at $\mathrm{m} / \mathrm{z} 681.7$ (i), and the total ion current (j). 

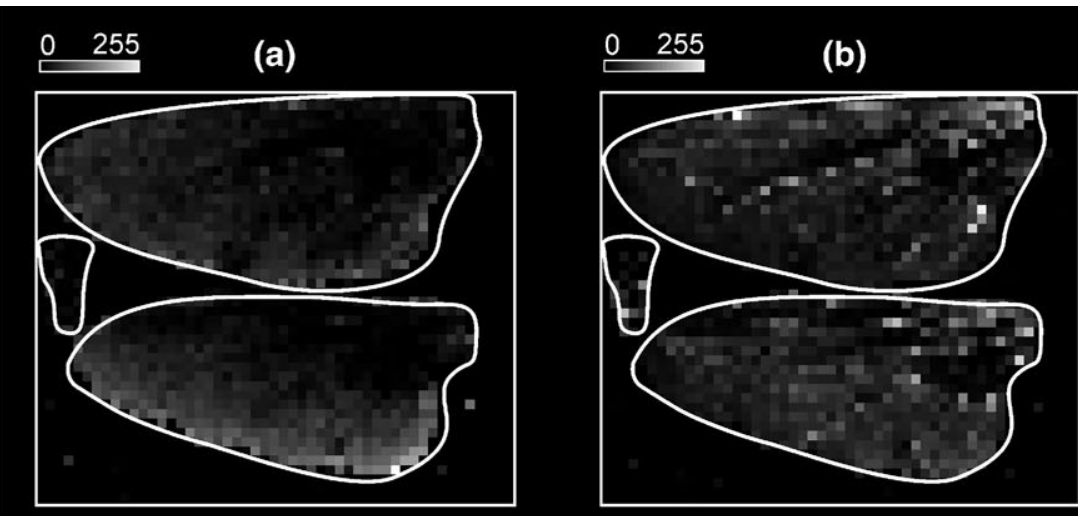

\section{$\underline{2 \mathrm{~mm}}$}

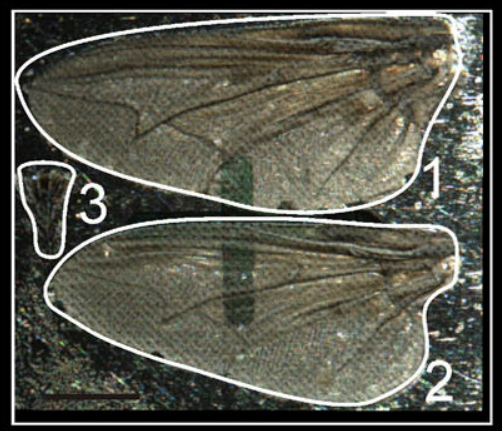

(d)

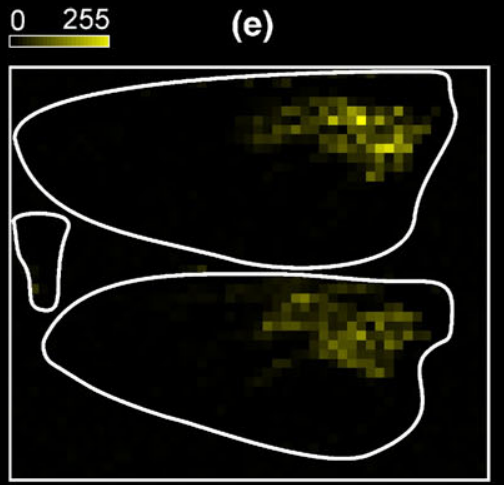

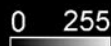

(c)

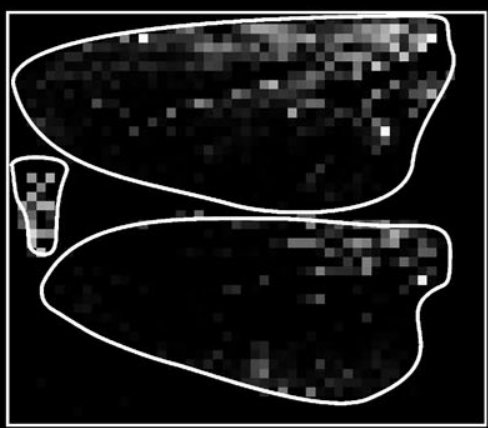

$0 \quad 255$

(f)

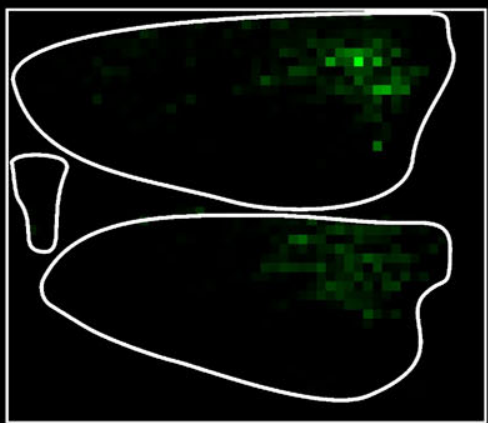

Figure 4. MALDI images of $N$. bullata male wing covered with sublimed DHB constructed in invert scale for DHB adducts with proton at $m / z 155.0(\mathbf{a})$, sodium at $m / z 177.0(\mathbf{b})$, potassium at $m / z 193.0$ (c), and photograph (after measurement) (d). MALDI images constructed for sodium $(\mathrm{m} / \mathrm{z} 697.7)$ (e) and potassium $\left(\mathrm{m} / z\right.$ 713.7) (f) adduct of $\mathrm{WE} \mathrm{C}_{46} \mathrm{H}_{90} \mathrm{O}_{2}$; dorsal side of the wing (1), ventral side of wing (2), low tarsus (3).

the cationization of WEs to occur (Figure 4e, f). The distribution of $\mathrm{C}_{46} \mathrm{H}_{90} \mathrm{O}_{2}$ as $[\mathrm{DHB}+\mathrm{K}]^{+}$observed in this experiment confirmed the previous results obtained with LiDHB and NaDHB (higher concentration of WEs near the wing basicosta). Note that the spatial distribution of the metal ions themselves does not follow patterns of any lipid imaged in this work.

\section{MALDI Imaging of D. melanogaster Wings}

Hydrocarbon monoenes or dienes are important for inter-specific communication in D. melanogaster [9]. As dienes were successfully imaged from $N$. bullata, we have probed $D$. melanogaster wings. The wings were gently cut from immobilized imagoes and sprayed with LiDHB as above. Because of small size of the wings, a high spatial resolution ( $254 \mathrm{dpi}$; step size $100 \mu \mathrm{m}$ ) was used. The matrix was deposited uniformly (Figure 5a) and also TIC showed rather uniform signal across the wings (Figure 5b). The expected $\mathrm{C}_{27} \mathrm{H}_{52}$ and $\mathrm{C}_{29} \mathrm{H}_{56}$ dienes were visible (Figure $5 c, d$ ), but only low intensity signals were obtained, presumably because of very thin wax layer. The basicosta-specific hydrocarbon distribution observed in N. bullata wings was not observed.
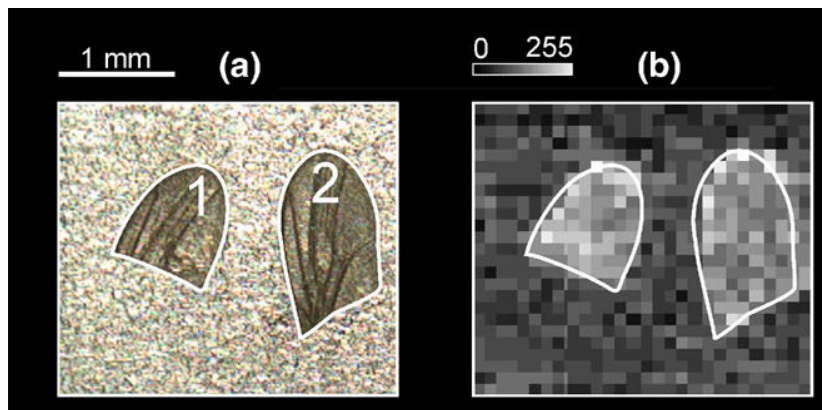

$0 \quad 255$

(c)

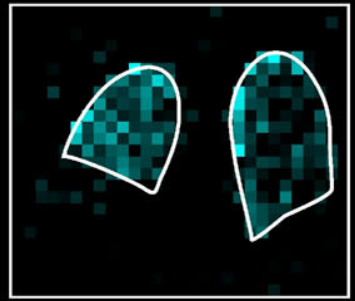

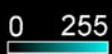

(d)

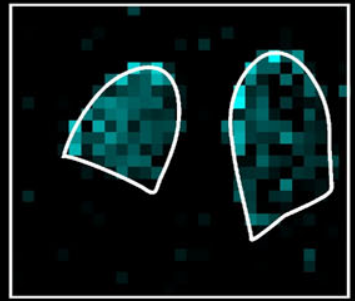

Figure 5. Photograph of D. melanogaster wing covered by LiDHB (a), MALDI images constructed for total ion current (b), lithium adduct of diene $\mathrm{HC} \mathrm{C}_{27} \mathrm{H}_{52}$ at $m / z 383.4$ (c), and diene $\mathrm{HC}_{29} \mathrm{H}_{56}$ at $m / z$ $411.4(\mathbf{d})$. 


\section{MALDI Imaging of Phoenix sp. Leaf}

Neutral lipids on both surfaces of Phoenix sp. leaf were imaged after spraying with LiDHB. High quality MALDI spectra (Figure 6d) were obtained. The ions were mostly lithium adducts of WEs; three of them $(\mathrm{m} / \mathrm{z}$ 683.7, 711.7, and 739.8 corresponding to $\left[\mathrm{M}+{ }^{6} \mathrm{Li}\right]^{+}$of $\mathrm{C}_{46} \mathrm{H}_{92} \mathrm{O}_{2}, \mathrm{C}_{48} \mathrm{H}_{96} \mathrm{O}_{2}$, and $\mathrm{C}_{50} \mathrm{H}_{100} \mathrm{O}_{2}$ ) were combined to construct a cumulative mass image of WEs (Figure 6b). Quite homogenous distribution of saturated WEs was observed. The matrix was deposited evenly as documented by photo and a TIC image (Figure 6a, c). No sodium or potassium adducts were observed, implicating negligible abundance of alkali metal cations on palm leaf surfaces.

\section{MALDI Imaging of A. thaliana Leaf}

Dorsal surface of $A$. thaliana leaf was imaged for WEs. Figure 6f shows distribution of $\mathrm{m} / \mathrm{z}$ 683.7, which is presumably saturated $W E \mathrm{C}_{46} \mathrm{H}_{92} \mathrm{O}_{2}$ identified previously [52]. Stronger signals were observed on the lamina, weaker on the petiole. Mass spectra showed also numer-
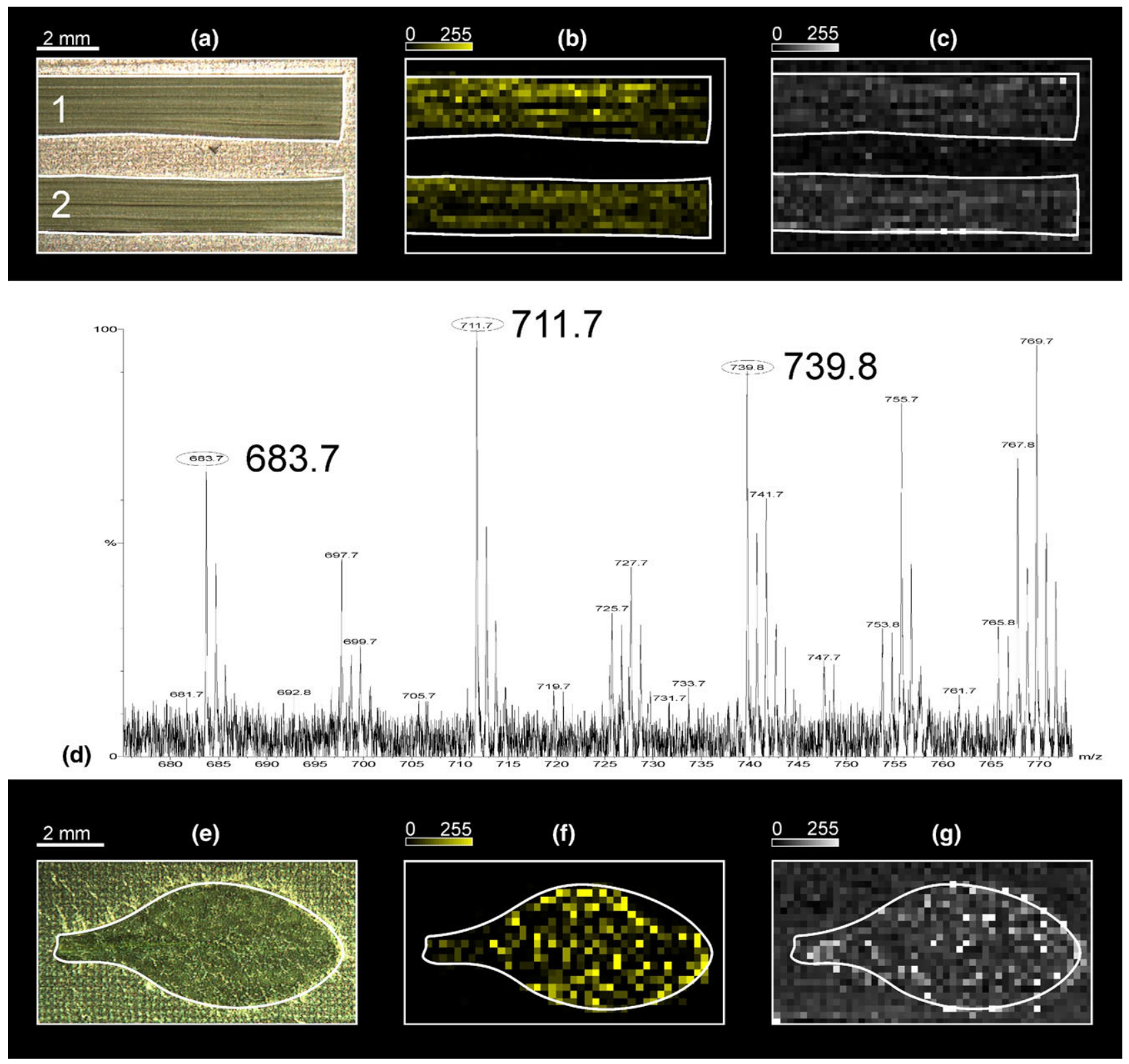

Figure 6. Photograph of Phoenix sp. leaf covered with LiDHB (after measurement) (a), MALDI images constructed for sum of lithium adduct of WEs $\mathrm{C}_{46} \mathrm{H}_{92} \mathrm{O}_{2}$ at $m / z$ 683.7, $\mathrm{C}_{48} \mathrm{H}_{96} \mathrm{O}_{2}$ at $\mathrm{m} / z$ 711.7, and $\mathrm{C}_{50} \mathrm{H}_{100} \mathrm{O}_{2}$ at $m / z 739.8(\mathbf{b})$, and the total ion current (c); dorsal surface (1), ventral surface (2). An example of MALDI imaging spectrum of Phoenix sp. leave (d). Photograph of $A$. thaliana leaf covered with LiDHB (after measurement) (e), MALDI images constructed for lithium adduct of WEs $\mathrm{C}_{46} \mathrm{H}_{92} \mathrm{O}_{2}$ at $m / z 683.7$ (f), and the total ion current $(\mathbf{g})$. 
ous compounds other then WEs. Strong signals were observed mainly on the lamina edges, which is apparent from a TIC image (Figure 6g). Imaging WEs on $A$. thaliana is a challenging task because of their low concentrations. They make up only about $1 \%$ of all extractable lipids [11]. Moreover, epidermal hairs on $A$. thaliana leaves might negatively affect deposition of matrix.

\section{Conclusions}

The results demonstrate that MALDI imaging can be used successfully on neutral, highly hydrophobic compounds such as HCs or WEs. As these are usually found on the outermost tissues in living organisms, imaging is performed directly from cuticular surfaces. Suitable matrices have to be used to achieve ionization. Alkali metal salts of DHB proved to work well; lithium salt (LiDHB) in particular appeared to be the most versatile matrix, enabling a majority of (if not all) neutral lipids to be detected. The matrix is best sprayed using an airbrush, which allows homogenous deposits to form and prevents the artificial redistribution of the analytes. Laser irradiation times are longer than for polar compound imaging, as nonpolar lipids ionize less willingly. Nevertheless, good quality spectra were recorded, allowing us to construct spatially resolved mass images. However, if wax esters only are of interest, the number of laser shots could be lowered. It may speed-up the imaging experiment or allows higher spatial resolution. Neutral lipids and related compounds are known to mediate chemical signals in various insect and plant species. The technique developed here is currently applied to study the semiochemicals of fruit flies, especially of $D$. melanogaster with spatial resolution 100 $\mu \mathrm{m}$. The first results with this small fly are encouraging, and will be published elsewhere. MALDI imaging is thus a worthwhile tool with which to solve various fundamental biological puzzles. Moreover, DHB matrix (preferably deposited by sublimation) allows us to visualize the distribution of sodium or potassium and, thus, to study processes involving alkali metal ions.

\section{Acknowledgments}

The authors gratefully acknowledge financial support by the Max Planck Society. The authors thank the Academy of Sciences of the Czech Republic (project no. AV0Z40550506-I058 and research project Z4 055 0506) and the Czech Science Foundation GACR (project no. 203/09/ 0139) for financial support. The authors are indebted to Dr. Karel Stránský for WEs standards, Mrs. Jarmila Titzenthalerová for insect samples, Dr. Jan Šobotník and Mr. Miroslav Hyliš for help with SEM, and Mrs. Emily Wheeler for editing the text.

\section{Appendix A Supplementary Material}

Supplementary material associated with this article may be found in the online version at doi:10.1016/ j.jasms.2009.10.003.

\section{References}

1. Brucker, J. S. Cuticular Polar Lipids of Insects. In Insect Lipids: Chemistry, Biochemistry, and Biology, Stanley-Samuelson, D. W.; Nelson, D. R., Eds.; University of Nebraska Press: Lincoln, NE, 1993; pp 227-270.

2. Nelson, D. R.; Blomquist, G. J. Insect Waxes. In Waxes: Chemistry, Molecular Biology, and Functions, Hamilton, R. J., Ed.; The Oily Press: Dundee, Scotland, 1995; pp 1-90.

3. Blomquist, G. J.; Howard, R. W. Pheromone biosynthesis in social insects. In Insect Pheromone Biochemistry and Molecular Biology: The Biosynthesis and Detection of Pheromones and Plant Volatiles, Blomquist, G. J.; Vogt, R. G., Eds.; Academic Press: London, UK, 2003; p. 332.

4. Howard, R. W.; Blomquist, G. J. Ecological, Behavioral, and Biochemical Aspects of Insect Hydrocarbons. Annu. Rev. Entomol. 2005, 50, 371-393.

5. Howard, R. W. Cuticular Hydrocarbons and Chemical Communication. In Insect Lipids: Chemistry, Biochemistry and Biology, Stanley-Samuelson, D. W.; Nelson, D. R., Eds.; University of Nebraska Press: Lincoln, NE, 1993; pp 179-226.

6. Espelie, K. E.; Bernays, E. A.; Brown, J. J. Plant and Insect Cuticular Lipids Serve as Behavioral Cues for Insects. Arch. Insect. Biochem. Physiol. 1991, 17, 223-233.

7. Juniper, B. E. Waxes on Plant Surfaces and Their Interactions with Insects. In Waxes: Chemistry, Molecular Biology, and Functions, Hamilton, R. J., Ed.; The Oily Press: Dundee, Scotland, 1995; pp 157-174.

8. Haverty, M. I.; Nelson, L. J. Cuticular Hydrocarbons of Reticulitermes (Isoptera rhinotermitidae) from Northern California Indicate Undescribed Species. Comp. Biochem. Physiol. B Biochem. Mol. Biol. 1997, 118, 869-880.

9. Ferveur, J. F. The Pheromonal Role of Cuticular Hydrocarbons in Drosophila melanogaster. Bioessays 1997, 19, 353-358.

10. Bianchi, G. Plant Waxes. In Waxes: Chemistry, Molecular Biology, and Functions, Hamilton, R. J., Ed.; The Oily Press: Dundee, Scotland, 1995; pp 175-222.

11. Kunst, L.; Samuels, A. L. Biosynthesis and Secretion of Plant Cuticular Wax. Prog. Lipid Res. 2003, 42, 51-80.

12. Samuels, L.; Kunst, L.; Jetter, R. Sealing Plant Surfaces: Cuticular Wax Formation by Epidermal Cells. Annu. Rev. Plant. Biol. 2008, 59, 683-707.

13. Post-Beittenmiller, D. Biochemistry and Molecular Biology of Wax Production in Plants. Annu. Rev. Plant Physiol. Plant. Mol. Biol. 1996, 47, 405-430.

14. Neinhuis, C.; Koch, K.; Barthlott, W. Movement and Regeneration of Epicuticular Waxes Through Plant Cuticles. Planta 2001, 213, 427-434.

15. Bargel, H.; Koch, K.; Cerman, Z.; Neinhuis, C. Structure-Function Relationships of the Plant Cuticle and Cuticular Waxes-a Smart Material? Funct. Plant. Biol. 2006, 33, 893-910.

16. Christie, W. W. Lipid Analysis; The Oily Press: Bridgewater, England, 2003; pp 105-372.

17. Christie, W. W. Gas Chromatography and Lipids. A Practical Guide; The Oily Press: Ayr, Scotland, 1989; pp 64-80.

18. Byrdwell W. C. Atmospheric Pressure Ionization Techniques in Modern Lipid Analysis. In Modern Methods for Lipid Analysis by Liquid Chromatography/Mass Spectrometry and Related Techniques, Byrdwell, W. C., Ed.; AOCS Press: Champaign, IL, 2005; p. 1-18.

19. Schiller, J.; Suss, R.; Arnhold, J.; Fuchs, B.; Lessig J.; Muller, M.; Petkovic, M.; Spalteholz, H.; Zschornig, O.; Arnold, K. Matrix-Assisted Laser Desorption and Ionization Time-of-Flight (MALDI-TOF) Mass Spectrometry in Lipid and Phospholipid Research. Prog. Lipid Res. 2004, 43, $449-488$.

20. Asbury, G. R.; Al-Saad, K.; Siems, W. F.; Hannan, R. M.; Hill, H. H. Analysis of Triacylglycerols and Whole Oils by Matrix-Assisted Laser Desorption/Ionization Time of Flight Mass Spectrometry. J. Am. Soc. Mass Spectrom. 1999, 10, 983-991.

21. Cvačka, J.; Svatoš, A. Matrix-Assisted Laser Desorption/Ionization Analysis of Lipids and High Molecular Weight Hydrocarbons with Lithium 2,5-Dihydroxybenzoate Matrix. Rapid Commun. Mass Spectrom. 2003, 17, 2203-2207.

22. Cvačka, J.; Jiroš, P.; Šobotník, J.; Hanus, R.; Svatoš, A. Analysis of Insect Cuticular Hydrocarbons Using Matrix-Assisted Laser Desorption/Ionization Mass Spectrometry. J. Chem. Ecol. 2006, 32, 409-434.

23. Vrkoslav, V.; Míková, R.; Cvačka, J. Characterization of Natural Wax Esters by MALDI-TOF Mass Spectrometry. J. Mass Spectrom. 2009, 44, 101-110.

24. Jetter, R.; Schaffer, S.; Riederer, M. Leaf Cuticular Waxes are Arranged in Chemically and Mechanically Distinct Layers: Evidence from Prunus laurocerasus L. Plant Cell Environ. 2000, 23, 619-628.

25. Waku, Y.: Manable, Y. Fine Structure of the Wax Gland in a Scale Insect, Eriococcus lagerstraemiae Kuwana (Homoptera: Eriococcidae). Appl. Entomol. Zoolog. 1981, 16, 94-102.

26. Foldi, I.; Pesrce, M. J. Fine Structure of Wax Glands, Wax Morphology, and Function in the Female Scale Insect, Pulvinaria regalis Canard. (Hemiptera: Coccidae). Int. J. Insect Morphol. Embryol. 1985, 14, 259-271.

27. McDonnell, L. A.; Heeren, R. M. A. Imaging mass spectrometry. Mass Spectrom. Rev. 2007, 26, 606-643.

28. Monroe, E. B.; Jurchen. J. C.; Lee, J.; Rubakhin, S. S.; Sweedler, J. V. Vitamin E Imaging and Localization in the Neuronal Membrane. J. Am. Chem. Soc. 2005, 127, 12152-12153.

29. Touboul, D.; Roy, S.; Germain, D. P.; Chaminade, P.; Brunelle, A.; Laprevote, O. MALDI-TOF and Cluster-TOF-SIMS Imaging of Fabry Disease Biomarkers. Int. J. Mass Spectrom. 2007, 260, 158-165. 
30. Tahallah, N.; Brunelle, A.; Porte, S.; Laprevote, O. Lipid Mapping in Human Dystrophic Muscle by Cluster-Time-of-Flight Secondary Ion Mass Spectrometry Imaging. J. Lipid Res. 2008, 49, 438-454.

31. Schwartz, S. A.; Reyzer, M. L.; Caprioli, R. M. Direct Tissue Analysis Using Matrix-Assisted Laser Desorption/Ionization Mass Spectrometry: Practical Aspects of Sample Preparation. J. Mass Spectrom. 2003, 38, 699-708.

32. Hankin, J. A.; Barkley, R. M.; Murphy, R. C. Sublimation as a Method of Matrix Application for Mass Spectrometric Imaging. J. Am. Soc. Mass Spectrom. 2007, 18, 1646-1652.

33. Puolitaival, S. M.; Burnum, K. E.; Cornett, D. S.; Caprioli, R. M. Solvent-Free Matrix Dry-Coating for MALDI Imaging of Phospholipids. J. Am. Soc. Mass Spectrom. 2008, 19, 882-886.

34. Chen, Y.; Allegood, J.; Liu, Y.; Wang, E.; Cachon-Gonzalez, B.; Cox, T. M.; Merrill A. H.; Sullards, M. C. Imaging MALDI Mass Spectrometry Using an Oscillating Capillary Nebulizer Matrix Coating System and Its Application to Analysis of Lipids in Brain from a Mouse Model of Tay-Sachs/Sandhoff Disease. Anal. Chem. 2008, 80, 2780-2788.

35. Caprioli, R. M.; Farmer, T. B.; Gile, J. Molecular Imaging of Biological Samples: Localization of Peptides and Proteins using MALDI-TOF MS. Anal. Chem. 1997, 69, 4751-4760.

36. Chaurand, P.; Caprioli, R. M. Direct Profiling and Imaging of Peptides and Proteins from Mammalian Cells and Tissue Sections by Mass Spectrometry. Electrophoresis 2002, 18, 3125-3135.

37. Wang, H.-Y. J.; Jackson, S. N.; McEuen, J.; Woods, A. S. Localization and Analyses of Small Drug Molecules in Rat Brain Tissue Sections. Anal. Chem. 2005, 77, 6682-6686.

38. Khatib-Shahidi, S.; Andersson, M.; Herman, J. L.; Gillespie, T. A.; Caprioli, R. M. Direct Molecular Analysis of Whole-Body Animal Tissue Sections by Imaging MALDI Mass Spectrometry. Anal. Chem. 2006, 78, 6448-6456.

39. Hsieh, Y.; Casale, R.; Fukuda, E.; Chen, J.; Knemeyer, I.; Wingate, J.; Morrison, R.; Korfmacher, W. Matrix-Assisted Laser Desorption/Ionization Imaging Mass Spectrometry for Direct Measurement of Clozapine in Rat Brain Tissue. Rapid Commun. Mass Spectrom. 2006, 20, 965-972.

40. Shroff, R.; Vergara, F.; Muck, A.; Svatos, A.; Gershenzon, J. Nonuniform Distribution of Glucosinolates in Arabidopsis thaliana Leaves Has Impor- tant Consequences for Plant Defense. Proc. Natl. Acad. Sci. U.S.A. 2008, 105, 6196-6201.

41. Rujoi, M.; Estrada, R.; Yappert, M. C. In situ MALDI-TOF MS Regional Analysis of Neutral Phospholipids in Lens Tissue. Anal. Chem. 2004, 76, 1657-1663.

42. Woods, A. S.; Jackson, S. N. Brain Tissue Lipidomics: Direct Probing Using Matrix-Assisted Laser Desorption/Ionization Mass Spectrometry. AAPS J. 2006, 8, E391-E395.

43. Jones, J. J.; Borgmann, S.; Wilkins, C. L.; O'Brien, R. M. Characterizing the Phospholipid Profiles in Mammalian Tissues by MALDI FTMS Anal. Chem. 2006, 78, 3062-3071.

44. Trim, P. J.; Atkinson, S. J.; Princivalle, A. P.; Marshall, P. S.; West, A.; Clench, M. R. Matrix-Assisted Laser Desorption/Ionization Mass Spectrometry Imaging of Lipids in Rat Brain Tissue with Integrated Unsupervised and Supervised Multivariant Statistical Analysis. Rapid Commun. Mass Spectrom. 2008, 22, 1503-1509.

45. Stransky, K.; Jursik, T. Simple Quantitative Transesterification of Lipids. 1. Introduction. Fett/Lipid 1996, 98, 65-71.

46. Aasen, A. J.; Hofstetter, H. H.; Iyengar, B. T. R.; Holman, R. T. Identification and Analysis of Wax Esters by Mass Spectrometry. Lipids 1971, 6, 502-507.

47. Jackson, L. L.; Armold, M. T.; Regnier, F. E. Cuticular Lipids of Adult Fleshflies Sarcophaga bullata. Insect Biochem. 1974, 4, 369-379.

48. Armold, M. T.; Regnier, F. E. A Developmental Study of the Cuticular Hydrocarbons of Sarcophaga bullata. J. Insect. Physiol. 1975, 21, 1827-1833.

49. Jallon, J. M.; David, J. R. Variations in Cuticular Hydrocarbons Along the Eight Species of the Drosophila melanogaster subgroup. Evolution 1987, 41, 294-302.

50. Yew, J. Y.; Cody, R. B.; Kravitz, E. A Cuticular Hydrocarbon Analysis of an Awake Behaving Fly Using Direct Analysis in Real-Time Time-ofFlight Mass Spectrometry. Proc. Natl. Acad. Sci. U.S.A. 2008, 20, 71357140 .

51. Garcia, B.; Marco, J. A.; Seoane, E.; Tortajada, A. Triterpenes, Waxes, and Tricin in Phoenix canariensis. J. Nat. Prod. 1981, 44, 111-113.

52. Lai, C.; Kunst, L.; Jetter, R. Composition of Alkyl esters in the Cuticular Wax on Inflorescence Stems of Arabidopsis thaliana cer mutants. Plant J. 2007, 50, 189-196. 